\title{
Competition for Hydrogen Prevents Coexistence of Human Gastrointestinal Hydrogenotrophs in Continuous Culture
}

\author{
Nick W. Smith ${ }^{1,2,3,4}$, Paul R. Shorten ${ }^{2,3 *}$, Eric Altermann ${ }^{2,4}$, Nicole C. Roy ${ }^{2,4,5,6}$ and \\ Warren C. McNabb ${ }^{2,5}$
}

${ }^{1}$ School of Food and Advanced Technology, Massey University, Palmerston North, New Zealand, ${ }^{2}$ Riddet Institute, Massey University, Palmerston North, New Zealand, ${ }^{3}$ AgResearch, Ruakura Research Centre, Hamilton, New Zealand, ${ }^{4}$ AgResearch, Grasslands Research Centre, Palmerston North, New Zealand, ${ }^{5}$ High-Value Nutrition National Science Challenge, Auckland, New Zealand, ${ }^{6}$ Liggins Institute, The University of Auckland, Auckland, New Zealand

OPEN ACCESS

Edited by:

Ulrike Kappler,

University of Queensland, Australia

Reviewed by:

Fang Zhang,

Fujian Agriculture and Forestry

University, China

Emily C. Hoedt,

University College Cork, Ireland

*Correspondence:

Paul R. Shorten

paul.shorten@agresearch.co.nz

Specialty section:

This article was submitted to Microbial Physiology and Metabolism,

a section of the journal

Frontiers in Microbiology

Received: 22 January 2020 Accepted: 29 April 2020

Published: 29 May 2020

Citation:

Smith NW, Shorten PR, Altermann E,

Roy NC and MCNabb WC (2020)

Competition for Hydrogen Prevents

Coexistence of Human

Gastrointestinal Hydrogenotrophs in

Continuous Culture.

Front. Microbiol. 11:1073.

doi: 10.3389/fmicb.2020.01073
Understanding the metabolic dynamics of the human gastrointestinal tract (GIT) microbiota is of growing importance as research continues to link the microbiome to host health status. Microbial strains that metabolize hydrogen have been associated with a variety of both positive and negative host nutritional and health outcomes, but limited data exists for their competition in the GIT. To enable greater insight into the behaviour of these microbes, a mathematical model was developed for the metabolism and growth of the three major hydrogenotrophic groups: sulphate-reducing bacteria (SRB), methanogens and reductive acetogens. In batch culture simulations with abundant sulphate and hydrogen, the SRB outcompeted the methanogen for hydrogen due to having a half-saturation constant $10^{6}$ times lower than that of the methanogen. The acetogen, with a high model threshold for hydrogen uptake of around $70 \mathrm{mM}$, was the least competitive. Under high lactate and zero sulphate conditions, hydrogen exchange between the SRB and the methanogen was the dominant interaction. The methanogen grew at $70 \%$ the rate of the SRB, with negligible acetogen growth. In continuous culture simulations, both the SRB and the methanogen were washed out at dilution rates above $0.15 \mathrm{~h}^{-1}$ regardless of substrate availability, whereas the acetogen could survive under abundant hydrogen conditions. Specific combinations of conditions were required for survival of more than one hydrogenotroph in continuous culture, and survival of all three was not possible. The stringency of these requirements and the inability of the model to simulate survival of all three hydrogenotrophs in continuous culture demonstrates that factors outside of those modelled are vital to allow hydrogenotroph coexistence in the GIT.

Keywords: microbiome, hydrogen, mathematical modelling, methane, hydrogen sulphide, acetate, cross-feeding

\section{INTRODUCTION}

The human gastrointestinal tract (GIT) is home to a vast number of microbes that survive via metabolism of dietary and endogenous substrates, or via cross-feeding on molecules released by other members of the microbiota. Study of this metabolic network is challenged by the vast number of different strains and interactions present in the GIT microbiota of a single individual 
(Qin et al., 2010), as well as the inter-individual differences in microbiota profile and variation in this profile over time (Healey et al., 2017). However, the increasing number of links between diet, the microbiota and host health motivate greater understanding of the microbial community (Zmora et al., 2019).

For research purposes, the microbiota is often divided into functional groups based on metabolic substrates and products common to the group [for example, see Kalyuzhnyi and Fedorovich (1998), Motelica-Wagenaar et al. (2014), and Kettle et al. (2015)]. The metabolic activity of saccharolytic functional groups results in the release of hydrogen (Carbonero et al., 2012). The accumulation of hydrogen in the GIT environment reduces the efficiency of carbohydrate breakdown via inhibition of coenzyme reoxidation (Thauer et al., 1977; Wolin and Miller, 1983). Hydrogen is removed from this environment via host absorption and excretion, but also via hydrogenotrophic microbes. There are three major functional groups that metabolize hydrogen: the sulphate-reducing bacteria (SRB), the methanogens and the reductive acetogens. Each of these hydrogenotrophic functional groups or their metabolic products have been linked to nutritional and health impacts upon the host: hydrogen sulphide, produced by the SRB, has been investigated for its genotoxic effect on the GIT epithelium (Attene-Ramos et al., 2010); methane, produced by the methanogens, has been associated with constipation (Ghoshal et al., 2016); and acetate, produced by the acetogens, is readily absorbed by the host for use as an energy source (Morrison and Preston, 2016), but can also be cross-fed upon by other members of the microbiota (Falony et al., 2006). Numerous other links between hydrogenotrophs and the host have also been researched, including roles in irritable bowel syndrome, inflammatory bowel disease, colorectal cancer and possible impacts on obesity (for reviews, see Carbonero et al., 2012 and Smith et al., 2019b).

To investigate the competition for hydrogen between the three hydrogenotrophic functional groups, a mathematical model for their growth and metabolism in batch or continuous culture was developed. There exist models for each of these functional groups in monoculture and for certain co-culture combinations. A thermodynamics-based monoculture model for SRB growth and metabolism has been published (Noguera et al., 1998) and there exist numerous models for microbial methanogenesis both in monoculture and in co-culture with a SRB (see Junicke et al., 2016; Lynch et al., 2019, and Muñoz-Tamayo et al., 2019 for recent examples). Tamayo et al. (2008) and D'Hoe et al. (2018) have produced models for reductive acetogens in monoculture and co-culture, respectively. However, as yet there exists no model examining the interactions of all three hydrogenotrophs and we are not aware of any tri-culture data for this combination. Thus, the modelling presented here provides an unprecedented theoretical insight into the dynamics of these interactions. This model includes the hydrogenotrophic metabolic pathways of each group, as well as lactate oxidation by the SRB, which can be a source of hydrogen. Much previous research has demonstrated a hierarchy in hydrogen uptake efficiency between these groups, with SRB having the greatest affinity for hydrogen and the acetogens the least (for a review, see Smith et al., 2019b), but there is currently no experimental data for the direct competition between the three groups for this substrate. The hypothesis here was that the model would reveal what conditions were necessary for hydrogenotroph coexistence, as well as the conditions that would favour one group over the others.

\section{MATERIALS AND METHODS}

\section{Mathematical Model}

The tri-culture model is the result of the additive combination of monoculture models for each of the three hydrogenotrophic functional groups. Both the SRB and acetogen components of the model are based on previously published model structures for Desulfovibrio vulgaris and Blautia hydrogenotrophica, respectively (Smith et al., 2019a, 2020), with minor notation alterations and the removal of mass transfer from the SRB model. Mass transfer is not included in the tri-culture model as the emphasis was on the ultimate outcome of cultures under various conditions, rather than the dynamics of the culture over time. The model also assumes that the culture media is homogeneously mixed, with no spatial component considered. The model structure is described below, with notation summarized in Table $\mathbf{1}$.

The following metabolic pathways are assumed for each hydrogenotroph:

Lactate metabolism by the SRB (Noguera et al., 1998): $\mathrm{CH}_{3} \mathrm{CHOHCOO}^{-}$(Lactate) $+2 \mathrm{H}_{2} \mathrm{O} \rightarrow \mathrm{CH}_{3} \mathrm{COO}^{-}$(Acetate) $+2 \mathrm{H}_{2}+\mathrm{H}^{+}+\mathrm{HCO}_{3}^{-}$(Bicarbonate)

Sulphate metabolism by the SRB (Noguera et al., 1998): $\mathrm{SO}_{4}^{2-}$ (Sulphate) $+5 \mathrm{H}_{2} \rightarrow \mathrm{H}_{2} \mathrm{~S}$ (Hydrogen sulphide) $+4 \mathrm{H}_{2} \mathrm{O}$

Hydrogen metabolism by the methanogen (Samuel et al., 2007): $4 \mathrm{H}_{2}+\mathrm{CO}_{2} \rightarrow \mathrm{CH}_{4}$ (Methane) $+2 \mathrm{H}_{2} \mathrm{O}$

Hydrogen metabolism by the acetogen (Schiel-Bengelsdorf and Dürre, 2012): $4 \mathrm{H}_{2}+2 \mathrm{CO}_{2} \rightarrow \mathrm{CH}_{3} \mathrm{COO}^{-}$(Acetate) + $\mathrm{H}^{+}+2 \mathrm{H}_{2} \mathrm{O}$

Note that the tri-culture model does not consider the concentrations of $\mathrm{H}_{2} \mathrm{O}, \mathrm{CO}_{2}$, bicarbonate or $\mathrm{H}^{+}$; these molecules are assumed abundant where required as substrates. In the case of the SRB, it is considered that $2.5 \mathrm{H}_{2}$ are produced, rather than $2 \mathrm{H}_{2}+\mathrm{H}^{+}$(Smith et al., 2019a).

Let $\mathcal{L}$ and $\mathcal{S}$ represent the rate of lactate and sulphate metabolism by the SRB, respectively:

$$
\begin{aligned}
& \mathcal{L}=\frac{u_{\max , L}}{Y_{S R B, L}} \frac{L}{L+K_{L}}\left(1-\frac{H}{H_{\max }}\right) X_{S R B} \\
& \mathcal{S}=\frac{u_{\max , S}}{Y_{S R B, S}} \frac{S}{S+K_{S}} \frac{H}{H+K_{S R B, H}} X_{S R B}
\end{aligned}
$$

These model equations are based on Monod kinetics (Monod, 1949), with the addition of a hydrogen inhibition term in the lactate metabolism equation (see Table 1 for definition of variables and parameters).

Next, let $\mathcal{M}$ and $\mathcal{A}$ be the rate of hydrogen metabolism by the methanogen and the acetogen respectively:

$$
\mathcal{M}=\frac{u_{\max , H}}{Y_{M E T}} \frac{H}{H+K_{M E T, H}} X_{M E T}
$$


TABLE 1 | Mathematical notation used in the model.

\begin{tabular}{|c|c|c|c|}
\hline Variables & Notation & $\begin{array}{c}\text { Value (if a } \\
\text { parameter) }\end{array}$ & Units \\
\hline Lactate concentration & $L$ & & $\mathrm{mM}$ \\
\hline Sulphate concentration & $S$ & & $\mathrm{mM}$ \\
\hline Hydrogen concentration & $H$ & & $\mathrm{mM}$ \\
\hline Acetate concentration & $A$ & & $\mathrm{mM}$ \\
\hline $\mathrm{H}_{2} \mathrm{~S}$ concentration & $P$ & & $\mathrm{mM}$ \\
\hline Methane concentration & $M$ & & $\mathrm{mM}$ \\
\hline Concentration of SRB cells & $X_{S R B}$ & & $g L^{-1}$ \\
\hline Concentration of methanogen cells & $X_{M E T}$ & & $g L^{-1}$ \\
\hline Concentration of acetogen cells & $X_{A C E}$ & & $g L^{-1}$ \\
\hline \multicolumn{4}{|l|}{ RATE TERMS } \\
\hline Lactate metabolism by SRB & $\mathcal{L}$ & & $\mathrm{mM} \mathrm{h}^{-1}$ \\
\hline Sulphate metabolism by SRB & $\mathcal{S}$ & & $\mathrm{mM} \mathrm{h}^{-1}$ \\
\hline Hydrogen metabolism by the methanogen & $\mathcal{M}$ & & $\mathrm{mM} \mathrm{h}^{-1}$ \\
\hline Hydrogen metabolism by the acetogen & $\mathcal{A}$ & & $\mathrm{mM} \mathrm{h}^{-1}$ \\
\hline Dilution rate & $D$ & & $\mathrm{~h}^{-1}$ \\
\hline Inflow rate of metabolite variable $i$ & $I_{i}$ & & $\begin{array}{c}\mathrm{mM} \mathrm{h}^{-1} \text { (since } \\
i \text { denotes a } \\
\text { metabolite) }\end{array}$ \\
\hline \multicolumn{4}{|l|}{ SRB PARAMETERS } \\
\hline Maximum growth rate for lactate & $\mu_{\max , L}$ & 0.116 & $h^{-1}$ \\
\hline Maximum growth rate for sulphate & $\mu_{\max , S}$ & 0.03 & $h^{-1}$ \\
\hline Growth yield during growth on lactate & $Y_{S R B, L}$ & 0.00565 & $\mathrm{~g} \mathrm{~L}^{-1} \mathrm{mM}^{-1}$ \\
\hline Growth yield during growth on sulphate & $Y_{S R B, S}$ & 0.00445 & $\mathrm{~g} \mathrm{~L}^{-1} \mathrm{mM}^{-1}$ \\
\hline Hydrogen inhibition parameter & $H_{\max }$ & 0.0216 & $\mathrm{mM}$ \\
\hline Half-saturation constant for lactate uptake & $K_{L}$ & 4.5 & $\mathrm{mM}$ \\
\hline $\begin{array}{l}\text { Half-saturation constant for sulphate } \\
\text { uptake }\end{array}$ & $K_{S}$ & 0.05 & $\mathrm{mM}$ \\
\hline $\begin{array}{l}\text { Half-saturation constant for hydrogen } \\
\text { uptake }\end{array}$ & $K_{S R B, H}$ & $1.69 \times 10^{-5}$ & $\mathrm{mM}$ \\
\hline $\begin{array}{l}\text { Moles of hydrogen produced per mole } \\
\text { lactate used }\end{array}$ & $b_{L H}$ & 2.5 & - \\
\hline $\begin{array}{l}\text { Moles of hydrogen used per mole } \mathrm{H}_{2} \mathrm{~S} \\
\text { produced }\end{array}$ & $b_{H P}$ & 5 & - \\
\hline $\begin{array}{l}\text { Moles of acetate produced per mole } \\
\text { lactate used }\end{array}$ & $b_{L A}$ & 1 & - \\
\hline $\begin{array}{l}\text { Moles of } \mathrm{H}_{2} \mathrm{~S} \text { produced per mole sulphate } \\
\text { used }\end{array}$ & $b_{S P}$ & 1 & - \\
\hline \multicolumn{4}{|l|}{ METHANOGEN PARAMETERS } \\
\hline Maximum growth rate $f$ & $\mu_{b \max , H}$ & 0.1042 & $\mathrm{~h}^{-1}$ \\
\hline Growth yield during growth on hydrogen & $Y_{M E T}$ & 0.0016 & $\mathrm{~g} \mathrm{~L}^{-1} \mathrm{mM}^{-1}$ \\
\hline $\begin{array}{l}\text { Half-saturation constant for hydrogen } \\
\text { uptake }\end{array}$ & $K_{M E T, H}$ & 10.63 & $\mathrm{mM}$ \\
\hline $\begin{array}{l}\text { Moles of methane produced per mole } \\
\text { hydrogen used }\end{array}$ & $b_{H M}$ & 0.0126 & - \\
\hline \multicolumn{4}{|l|}{ ACETOGEN PARAMETERS } \\
\hline Threshold parameter & $p_{1}$ & 0.015 & $\mathrm{mM}^{-1}$ \\
\hline Threshold parameter & $p_{2}$ & 336 & $\mathrm{mM}$ \\
\hline First order kinetics rate parameter & $\eta$ & 0.0054 & $\mathrm{~h}^{-1} \mathrm{mM}^{-1}$ \\
\hline Growth yield during growth on hydrogen & $Y_{A C E}$ & 0.0017 & $\mathrm{~g} \mathrm{~L}^{-1} \mathrm{mM}^{-1}$ \\
\hline Moles of acetate produced per mole & $b_{H A}$ & 0.25 & - \\
\hline
\end{tabular}

$$
\mathcal{A}=\frac{\eta}{Y_{A C E}} \frac{H}{1+\exp \left(p_{1}\left(p_{2}-H\right)\right)} X_{A C E}
$$

The rate of hydrogen metabolism by the acetogen is not based on Monod kinetics, but rather on first order kinetics with the incorporation of a threshold modelling term, adapted from Ribes et al. (2004). This term ensures a rapid decrease in hydrogen uptake at concentrations below $p_{2}$, with negligible uptake for concentrations below $70 \mathrm{mM}$, a previously derived threshold value for hydrogen uptake by the acetogen $B$. hydrogenotrophica (Leclerc et al., 1997; Smith et al., 2020). Using these rate terms, the full model is defined as the following system of ordinary differential equations (ODEs):

$$
\begin{aligned}
\frac{d L}{d t} & =-\mathcal{L} \\
\frac{d S}{d t} & =-\mathcal{S} \\
\frac{d H}{d t} & =b_{L H} \mathcal{L}-b_{H P} \mathcal{S}-\mathcal{M}-\mathcal{A} \\
\frac{d A}{d t} & =b_{L A} \mathcal{L}+b_{H A} \mathcal{A} \\
\frac{d P}{d t} & =b_{S P} \mathcal{S} \\
\frac{d M}{d t} & =b_{H M} \mathcal{M} \\
\frac{d X_{S R B}}{d t} & =Y_{S R B, L} \mathcal{L}+Y_{S R B, S} \mathcal{S} \\
\frac{d X_{M E T}}{d t} & =Y_{M E T} \mathcal{M} \\
\frac{d X_{A C E}}{d t} & =Y_{A C E} \mathcal{A}
\end{aligned}
$$

Note that when the model is applied to continuous culture conditions, the following terms are appended to each ODE:

$$
-D i+I_{i}
$$

Where $D$ is the dilution rate, $i$ denotes the state variable of the ODE to which the term is appended and $I_{i}$ is the inflow rate of $i$. In the cases considered here, $I_{i}$ is set to zero for all microbial state variables; only metabolite inflows are permitted to be non-zero.

\section{Parametrisation of the Methanogen Model}

Since the model for the methanogen is not based on a previously published model, a Monod model was fitted to monoculture experimental data. Data was obtained from Khelaifia et al. (2013) using graphical input and image capturing software in MATLAB (The MathWorks; www.mathworks.com). Cell concentration in $\mathrm{mg} \mathrm{ml}^{-1}$ was determined using the optical density (OD) conversion of: $\mathrm{mg} \mathrm{ml}^{-1}=0.462$. OD (Richards et al., 2016). Although this was originally calculated for Methanococcus maripaludis at a different wavelength, there was difficulty in finding reliable conversion factors for Methanobrevibacter smithii. Khelaifia and Drancourt (2012) previously published a 
methanogen conversion factor of $0.4 \cdot \mathrm{OD}=4.42^{12}$ cells $/ \mathrm{ml}$, which was calculated as approximately $\mathrm{mg} \mathrm{ml}^{-1}=0.236 \cdot$ OD. However, the strain measured by Khelaifia and Drancourt (2012) was unclear and the calculation required an approximation on the weight of individual cells, therefore the more reliable conversion factor of Richards et al. (2016) was used. The two conversion factors were similar, implying that the true value is close to this range.

Notably, the expected stoichiometry of 1 mole methane produced per 4 moles hydrogen consumed was not observed in the experimental monoculture data (Figure 1, Table 1). It is unclear why the yield of methane was reduced in this experiment. However, the kinetic parameters obtained from fitting were comparable with estimates in the literature (Muñoz-Tamayo et al., 2019). As the stoichiometric yield of methane has no

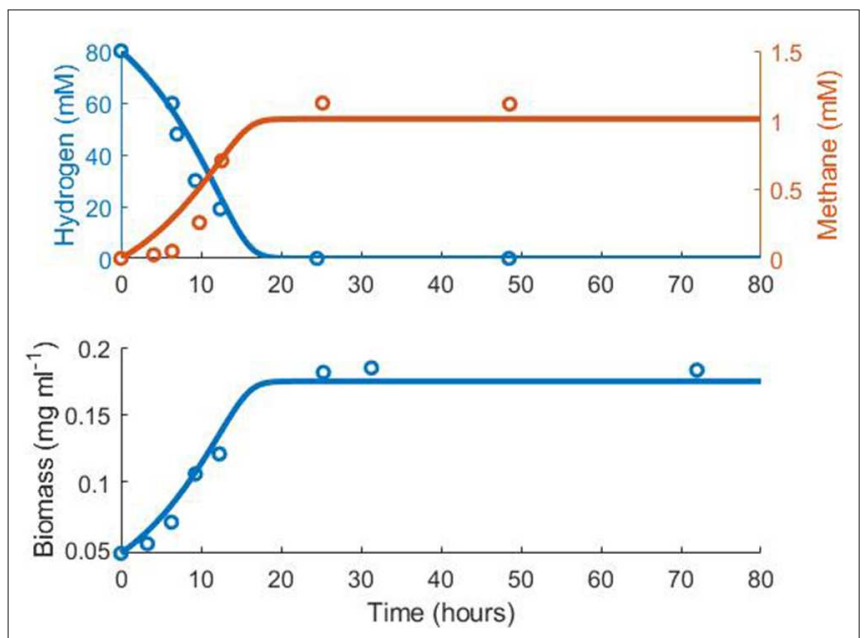

FIGURE 1 | Fit of the methanogen model to experimental data from Khelaifia et al. (2013). Hydrogen $R^{2}=0.75$, Methane $R^{2}=0.50$, Biomass $R^{2}=0.85$. influence on the interactions between the three hydrogenotrophs in the model, the fitted value was used in later modelling.

\section{Numerical Simulations}

For numerical analysis, the mathematical model was solved using the ode15s solver in MATLAB (The MathWorks; www. mathworks.com).

\section{RESULTS}

\section{Analysis of the Model Under Batch Culture Conditions}

A comparison of the half-saturation and threshold parameter values for the three hydrogenotrophs shows the hierarchy in affinities for this substrate: the model estimates for the hydrogen half-saturation constants of the SRB and the methanogen are $1.69 \times 10^{-5} \mathrm{mM}$ and $10.63 \mathrm{mM}$, respectively (Table 1 ), while the threshold for hydrogen uptake for the acetogen is estimated at around $70 \mathrm{mM}$ (Leclerc et al., 1997; Smith et al., 2020). As has been established by previous research, SRB generally have a greater affinity for hydrogen than the methanogens, which in turn have a greater affinity than the reductive acetogens for this substrate (for reviews, see Carbonero et al., 2012 and Smith et al., 2019b). For the acetogen in this model, growth limitation due to reduced substrate availability increases rapidly once the hydrogen concentration is below $336 \mathrm{mM}$. Using the parameter values in Table 1, the growth rate of the acetogen at this hydrogen concentration is $0.0069 \mathrm{~h}^{-1}$, which is small compared to the corresponding methanogen growth rate of 0.09 $\mathrm{h}^{-1}$ at this hydrogen concentration.

The complexity of the model equations, defined in the Materials and Methods section, precludes an analytical solution, but steady state analysis may still be performed. The first case considered is the batch culturing of all three hydrogenotrophs where lactate is the sole available substrate in the model. Under batch conditions with initially abundant lactate, the SRB will
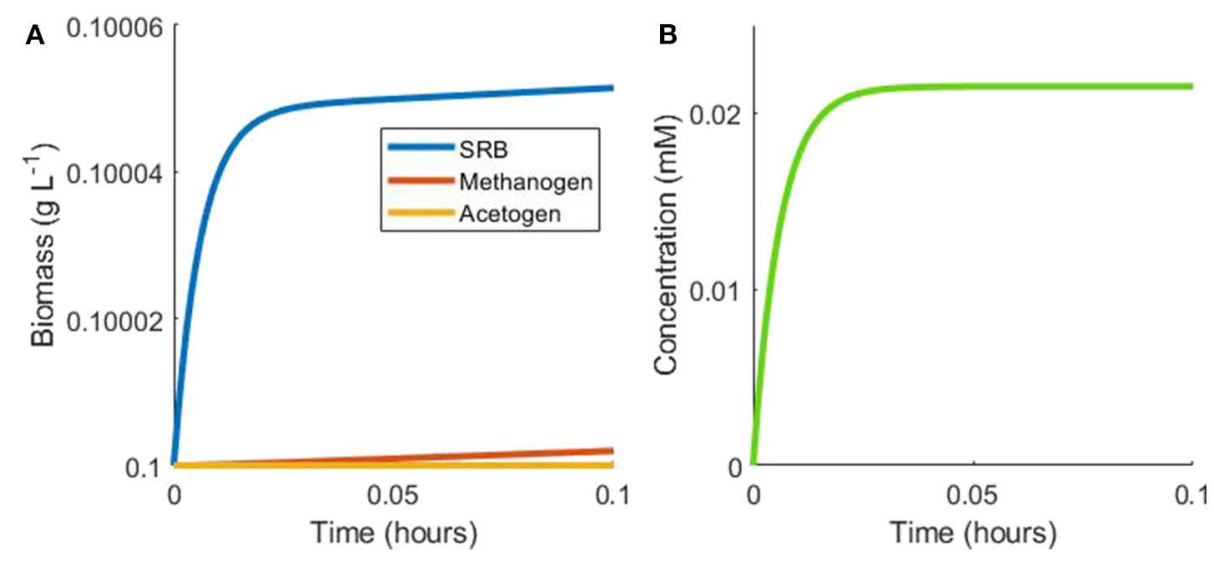

FIGURE 2 | Example simulation of early stages of batch tri-culture with lactate the sole added substrate. (A) Shows the change in microbial biomass over time and (B) shows the change in hydrogen concentration over time. The SRB rapidly oxidizes lactate to acetate and hydrogen, resulting in SRB growth and hydrogen accumulation. Once hydrogen accumulates to a level approaching the inhibitory concentration for SRB growth, its concentration remains in a pseudo-steady state with a balance between hydrogen production by the SRB and consumption by the methanogen. 

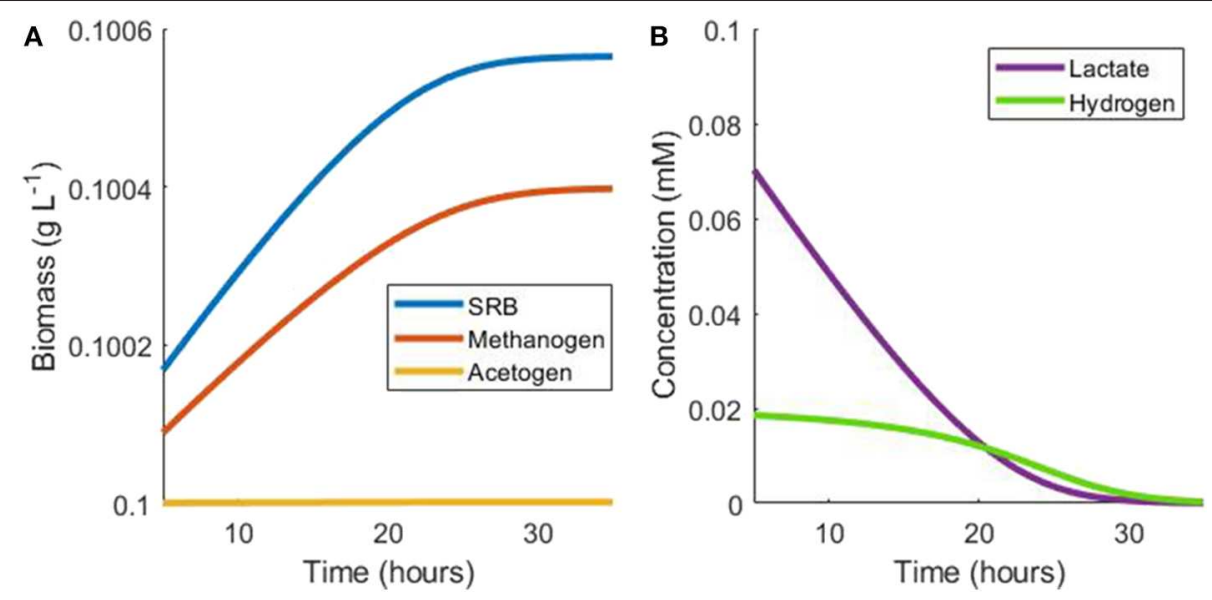

FIGURE 3 | Example simulation of late stages of batch tri-culture with lactate the sole added substrate. (A) Shows the change in microbial biomass over time and (B) shows the change in hydrogen and lactate concentrations over time. As lactate is depleted, hydrogen production ceases and ultimately both lactate and hydrogen are depleted by the SRB and the methanogen, respectively.

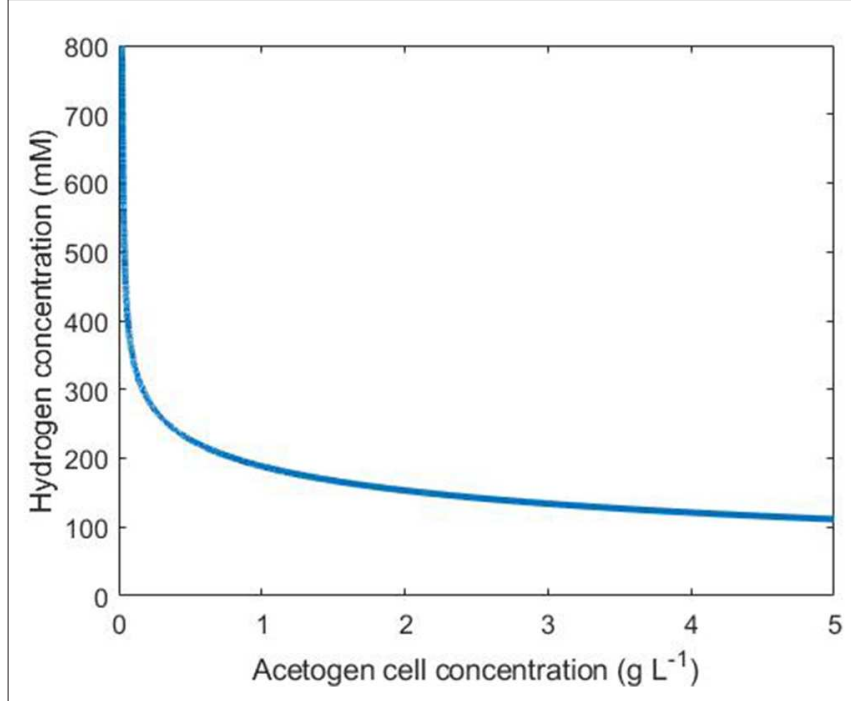

FIGURE 4 | Conditions necessary for an acetogen growth rate above $0.1 \mathrm{~g}$ $\mathrm{L}^{-1} \mathrm{~h}^{-1}$. The line indicates the threshold for this growth rate: any combination of hydrogen and cell concentrations falling to the upper/right side of this line results in a growth rate above 0.1 .

metabolize lactate to acetate and hydrogen rapidly, until the inhibitory hydrogen concentration is approached and growth is slowed (Figure 2). Growth would be halted completely under these conditions, but for the consumption of hydrogen by the other two hydrogenotrophs.

The acetogen's threshold for hydrogen uptake is greater than the inhibitory hydrogen concentration for the SRB: at the inhibitory hydrogen concentration for SRB, the growth rate of the acetogen, $\mathcal{A}=4.41 \times 10^{-4} X_{A C E}$, is very small, resulting in minimal acetogen growth under these conditions. The SRB inhibitory hydrogen concentration is also almost three orders of magnitude smaller than the half-saturation constant for hydrogen uptake by the methanogen, thus limiting methanogen growth, with methanogen growth rate of $\mathcal{M}=0.13 X_{M E T}$.

A pseudo-steady state is then reached for the hydrogen concentration at a level approaching the inhibitory concentration, which is maintained by low-rate hydrogen consumption by the methanogen and hydrogen production by the SRB. Assuming this steady state and thereby nullifying $\frac{d H}{d t}$, the growth rate of the methanogen is proportional to that of the SRB at this steady state:

$$
0=b_{L H} \mathcal{L}-\mathcal{M} \Rightarrow \frac{d X_{M E T}}{d t}=\frac{b_{L H} Y_{M E T}}{Y_{S R B, L}} \frac{d X_{S R B}}{d t} \approx 0.7 \frac{d X_{S R B}}{d t}
$$

Using the monoculture parameter values in Table $\mathbf{1}$ and assuming negligible growth by the acetogen, the growth rate of the methanogen is around $70 \%$ of the SRB growth rate in this situation. The population continues in this hydrogen steady state until lactate becomes depleted, at which point SRB growth is halted. As a result, hydrogen production ceases and hydrogen is then depleted by the methanogen, ultimately halting its growth (Figure 3).

If sulphate is also present in the medium in excess, hydrogen does not reach the inhibitory concentration due to its further use in the reduction of sulphate (data not shown). Again, negligible acetogen growth is possible at such a low hydrogen concentration. In numerical simulations (data not shown), the methanogens achieved only an incremental increase in biomass from hydrogen metabolism in this scenario, due to the hydrogen concentration remaining much lower than the methanogen halfsaturation constant.

If hydrogen is the sole model substrate available, then the SRB will not grow, due to the absence of sulphate. Both the methanogen and the acetogen grow under these conditions, but the methanogen will show greater growth at low hydrogen concentrations due to its greater affinity for this substrate. 
TABLE 2 | Outcomes of batch culture under various initial conditions.

\begin{tabular}{|c|c|c|c|c|c|c|c|}
\hline & \multicolumn{7}{|c|}{ Hydrogenotrophs in culture at initial time } \\
\hline & & SRB + Methanogen + Acetogen & $\begin{array}{l}\text { SRB + EITHER Methanogen } \\
\text { OR Acetogen }\end{array}$ & $\begin{array}{l}\text { Methanogen } \\
+ \text { Acetogen }\end{array}$ & SRB only & $\begin{array}{l}\text { Methanogen } \\
\text { only }\end{array}$ & $\begin{array}{l}\text { Acetogen } \\
\text { only }\end{array}$ \\
\hline \multirow[t]{7}{*}{$\begin{array}{l}\text { Substrates } \\
\text { available at } \\
\text { initial time }\end{array}$} & $\begin{array}{l}\text { Lactate + } \\
\text { Sulphate + } \\
\text { Hydrogen }\end{array}$ & $\begin{array}{l}\text { Growth of SRB, minimal growth of } \\
\text { methanogen and negligible growth } \\
\text { of acetogen due to out-competition } \\
\text { for hydrogen }\end{array}$ & $\begin{array}{l}\text { Growth of SRB, minimal growth } \\
\text { of other due to out-competition } \\
\text { for hydrogen }\end{array}$ & & & & \\
\hline & $\begin{array}{l}\text { Lactate + } \\
\text { Sulphate }\end{array}$ & $\begin{array}{l}\text { Growth of SRB, minimal growth of } \\
\text { methanogen and negligible growth } \\
\text { of acetogen due to out-competition } \\
\text { for hydrogen }\end{array}$ & $\begin{array}{l}\text { Growth of SRB, minimal growth } \\
\text { of other due to out-competition } \\
\text { for hydrogen }\end{array}$ & & & & \\
\hline & $\begin{array}{l}\text { Lactate }+ \\
\text { Hydrogen }\end{array}$ & $\begin{array}{l}\text { Growth of SRB when } H<H_{\max } \text {, } \\
\text { minimal growth of methanogen and } \\
\text { negligible growth of acetogen due } \\
\text { to out-competition for hydrogen } \\
\text { until } H>H_{\max } \text {, at which point SRB } \\
\text { growth halted, methanogen and } \\
\text { acetogen growth }\end{array}$ & $\begin{array}{l}\text { Growth of SRB when } H<H_{\max } \text {, } \\
\text { growth of other }\end{array}$ & & $\begin{array}{l}\text { Growth } \\
\text { when } \\
H<H_{\max }\end{array}$ & & \\
\hline & $\begin{array}{l}\text { Sulphate + } \\
\text { Hydrogen }\end{array}$ & $\begin{array}{l}\text { Growth of SRB, minimal growth of } \\
\text { others due to out-competition for } \\
\text { hydrogen }\end{array}$ & $\begin{array}{l}\text { Growth of SRB, minimal growth } \\
\text { of other due to out-competition } \\
\text { for hydrogen }\end{array}$ & & & & \\
\hline & Lactate only & $\begin{array}{l}\text { Slow growth of all as SRB } \\
\text { dependent on hydrogen removal by } \\
\text { others. More growth by } \\
\text { methanogen than acetogen due to } \\
\text { low hydrogen concentration }\end{array}$ & $\begin{array}{l}\text { Slow growth of both as SRB } \\
\text { dependent on hydrogen } \\
\text { removal by other }\end{array}$ & & $\begin{array}{l}\text { Growth until } \\
H \text { reaches } \\
H_{\max }\end{array}$ & & \\
\hline & Sulphate only & & & & & & \\
\hline & $\begin{array}{l}\text { Hydrogen } \\
\text { only }\end{array}$ & $\begin{array}{l}\text { No growth of SRB, growth of } \\
\text { methanogen, minimal growth of } \\
\text { acetogen due to out-competition } \\
\text { for hydrogen }\end{array}$ & $\begin{array}{l}\text { No growth of SRB, growth of } \\
\text { other }\end{array}$ & & & & \\
\hline
\end{tabular}

Green represents growth of all organisms, red represents no growth of any organisms, tan represents more complex dynamics.

At high hydrogen concentrations, the model predicts greater growth by the acetogen, since its growth rate increases linearly with the hydrogen concentration, whereas the methanogen's growth rate is limited to $\mu_{\max , H}$. However, the acetogen model was parameterized at hydrogen concentrations below $200 \mathrm{mM}$, therefore likely extrapolates poorly to concentrations above this range (Smith et al., 2020). For higher hydrogen concentrations, it is likely that a Monod formulation would be more appropriate in capturing the acetogen dynamics. However, such high concentrations are not expected in the GIT (Carbonero et al., 2012; Wolf et al., 2016), hence the use of the threshold model.

Under our assumptions on the simple tri-culture batch scenario, the acetogen achieves a growth rate of at least $G \mathrm{~g} \mathrm{~L}^{-1}$ $\mathrm{h}^{-1}$ if the hydrogen and acetogen cell concentrations satisfy

$$
X_{A C E}>G \frac{1+\exp \left(p_{1}\left(p_{2}-H\right)\right)}{\eta H}
$$

An interpretation of Equation 14 is shown in Figure 4, where points above and to the right of the line indicate conditions resulting in an acetogen growth rate of at least $G=0.1$.

It is important to note that in the batch tri-culture environment, the hydrogen concentration will rapidly decrease due to metabolism by the methanogen and the SRB (if sulphate is available). Therefore, the acetogen will only display growth in the early stages of culture when hydrogen is abundant.

Table 2 summarizes the outcomes of various initial culture conditions on batch culture growth of the three hydrogenotrophs.

\section{Analysis of the Model Under Continuous Culture Conditions}

Once dilution is introduced to the model, competition between the hydrogenotrophs for hydrogen becomes important in determining their survival. However, it is initially of importance to investigate what dilution rates allow for survival of each microbe individually. For a microbe to have the potential to survive continuous culture, its maximum growth rate must be greater than the dilution rate. The maximum growth rates of the SRB and the methanogen are $0.146 \mathrm{~h}^{-1}$ and $0.1042 \mathrm{~h}^{-1}$, respectively (Table 1), so they cannot survive in continuous culture with a greater dilution rate than these values. The maximum growth rate of the reductive acetogen is not as straightforward since under the current model structure it is determined in part by the hydrogen concentration. However, an acetogen growth rate of $0.1 \mathrm{~h}^{-1}$ would be achieved at a hydrogen concentration of $188 \mathrm{mM}$, therefore hydrogen concentrations 


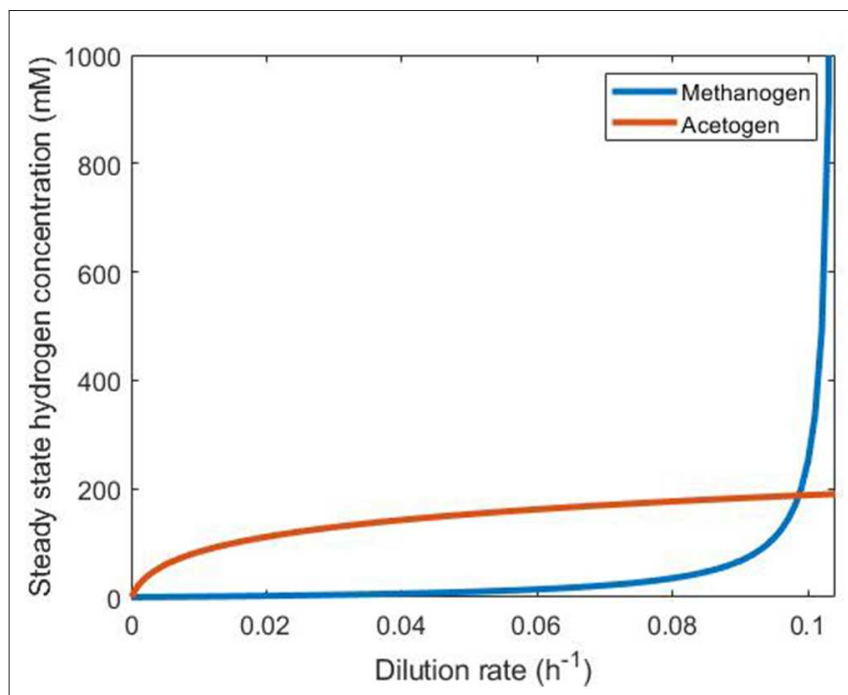

FIGURE 5 | Comparison of steady state hydrogen concentrations achieved by the methanogen and the reductive acetogen. The hydrogenotroph with the lower of the two steady state hydrogen concentrations at a given dilution rate will outcompete the other for this substrate and survive while the other is washed out. Beyond $\mathrm{D}=0.1042$, the methanogen growth rate cannot be greater than the dilution rate, so it is washed out irrespective of the presence of the acetogen.

exceeding this value would be required for the acetogen to survive a dilution rate $(D)$ above $0.1 \mathrm{~h}^{-1}$.

When growing solely by sulphate reduction in the absence of lactate, the maximum growth rate of the SRB is $0.03 \mathrm{~h}^{-1}$. Washout of this bacterium therefore occurs at dilution rates exceeding this value, regardless of the abundance of hydrogen and sulphate.

The first scenario considered is competition for hydrogen between the methanogen and the acetogen. This is analyzed via their respective non-trivial steady states. Assuming abundant hydrogen and a steady state cell concentration for the methanogen, it can be seen that:

$$
D=\mu_{\max , H} \frac{H}{H+K_{M E T, H}} \Rightarrow H=\frac{K_{M E T, H} D}{\mu_{\max , H}-D}
$$

Similarly, assuming steady state for the acetogen gives:

$$
D=\frac{\eta H}{1+\exp \left(p_{1}\left(p_{2}-H\right)\right)}
$$

Plotting the dilution rate against the steady state hydrogen concentration (Figure 5) allows determination of the persistence of each of these two hydrogenotrophs under abundant hydrogen conditions in continuous culture. The microbe that achieves the lower steady state hydrogen concentration at a given dilution rate will outcompete the other by reducing the concentration of this substrate below its competitor's steady state value, leading to washout of the competitor. It can be seen in Figure 5 that the methanogen is therefore the survivor at lower dilution rates, and the acetogen at greater dilution rates. The only dilution rate at

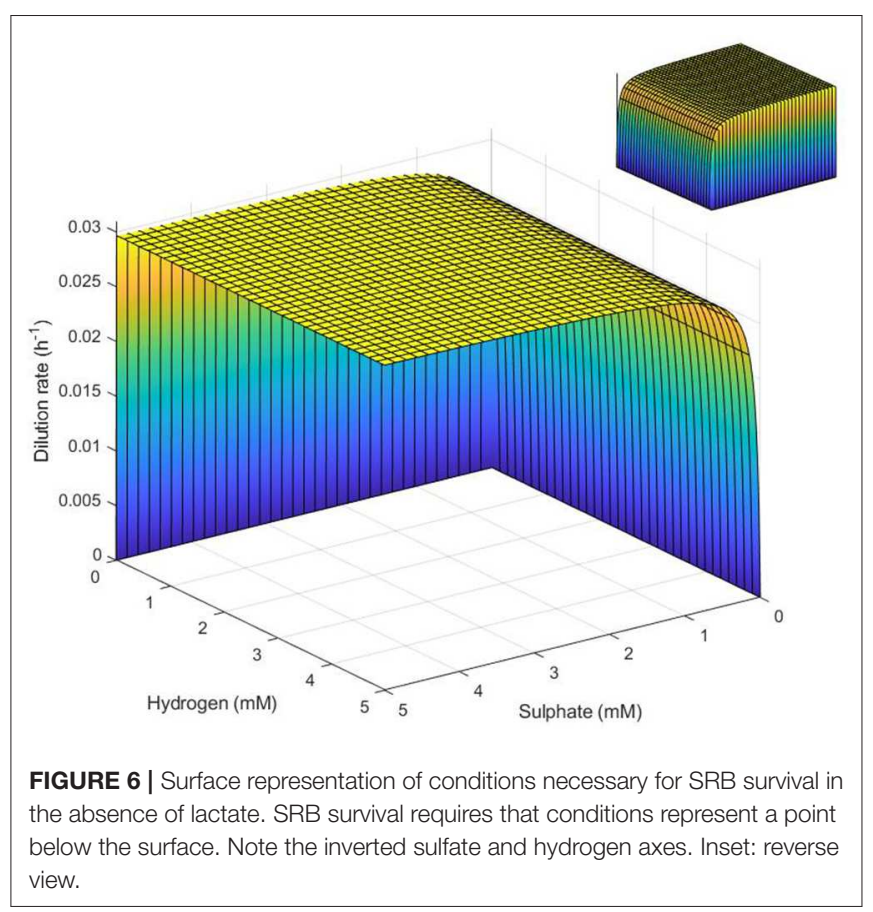

which the two may coexist is when their steady state hydrogen concentrations intersect, at a dilution rate of $\sim 0.09861 \mathrm{~h}^{-1}$. At this dilution rate, the methanogen and the acetogen can coexist, given abundant hydrogen availability.

The more diverse metabolic capabilities of the SRB mean that conditions for SRB survival are more complex. If no lactate is available to the $\mathrm{SRB}$, then survival requires that the dilution rate $D \leq u_{\max , s}=0.03$, the maximum growth rate of the SRB in the absence of lactate. Moreover, a non-negative SRB growth rate, $\frac{d X_{S R B}}{d t} \geq 0$, requires that

$$
D \leq \mu_{\max , S} \frac{S}{S+K_{S}} \frac{H}{H+K_{S R B, H}}
$$

The surface plot in Figure 6 demonstrates these conditions on the three key variables.

If lactate is available in the medium, but sulphate is not, survival requires that $D \leq u_{\max , L}=0.116$, the maximum growth rate of the SRB on lactate. Secondly, SRB growth is also impossible for hydrogen concentrations above $H_{\text {max }}$. Thirdly, there is also the requirement that

$$
\begin{aligned}
D \leq u_{\max , L} \frac{L}{L+K_{L}}\left(1-\frac{H}{H_{\max }}\right) & \leq u_{\max , L}\left(1-\frac{H}{H_{\max }}\right) \\
\Rightarrow H & \leq H_{\max }\left(1-\frac{D}{u_{\max , L}}\right)
\end{aligned}
$$

Figure 7 shows these conditions graphically using the parameter values in Table 1. Clearly, the third condition encapsulates the first two and is the most stringent under these parameter values.

We may also extract further, more complex conditions for SRB growth when lactate is the sole added substrate. Taking the steady state for the hydrogen differential equation under abundant 


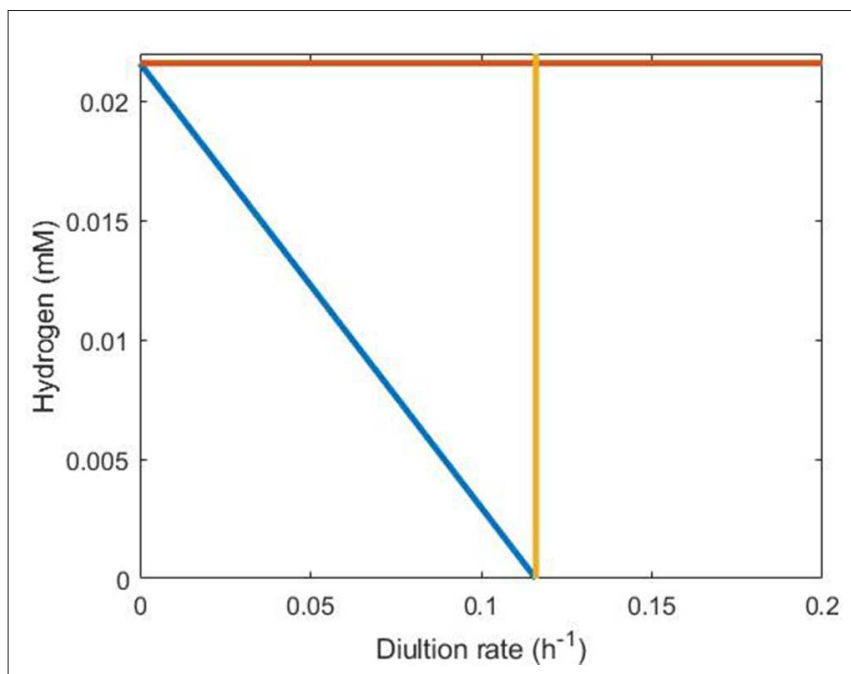

FIGURE 7 | Representation of conditions necessary for SRB survival in the absence of sulfate. The orange line indicates $H=H_{\max }$, the yellow line indicates $D=0.116$ and the blue line indicates the inequality derived in the text (Equation 18) between dilution rate and hydrogen concentration. SRB survival requires that steady state conditions lie below and to the left of all three lines, making the blue line clearly the strongest requirement.

lactate, no hydrogen inflow and with only the SRB present allows derivation of the steady state hydrogen concentration:

$$
\begin{aligned}
0 & =b_{L H} \frac{\mu_{\max , L}}{Y_{S R B, L}} X_{S R B}\left(1-\frac{H_{S S}}{H_{\max }}\right)-D H_{S S} \\
\Rightarrow H_{S S} & =b_{L H} \frac{\mu_{\max , L}}{Y_{S R B, L}} X_{S R B}\left(D+b_{L H} \frac{\mu_{\max , L}}{H_{\max } Y_{S R B, L}} X_{S R B}\right)^{-1}
\end{aligned}
$$

Substituting this value into the equation for the SRB growth rate under abundant lactate conditions and simplifying gives the SRB growth rate at steady state as:

$$
\mu_{\max , L}\left(1-\frac{H_{S S}}{H_{\max }}\right)=\frac{D H_{\max } \mu_{\max , L} Y_{S R B, L}}{\left(D H_{\max } Y_{S R B, L}+b_{L H} \mu_{\max , L} X_{S R B}\right)}
$$

Since this growth rate must be greater than or equal to the dilution rate to prevent washout, we may derive the following condition for SRB survival:

$$
D \leq \mu_{\max , L}\left(1-\frac{b_{L H} X_{S R B}}{H_{\max } Y_{S R B, L}}\right) \approx 0.116-2376 X_{S R B}
$$

Therefore, survival of the SRB requires that the cell concentration is $<\sim 4.88 \times 10^{-5} \mathrm{~g} \mathrm{~L}^{-1}$; any greater concentration would result in too rapid an accumulation of hydrogen and subsequent SRB inhibition. This constitutes a very small window for successful SRB continuous culture when lactate is the sole added substrate.

Moving on to the survival of co-cultures including the SRB, next analyzed is the coexistence of the SRB and the methanogen when no lactate is available. In this case, the steady state hydrogen concentrations for each in monoculture are

$$
H_{S S, S R B}=\frac{K_{S R B, H}}{\frac{\mu_{\max , S} S}{D\left(K_{S}+S\right)}-1}
$$

for the SRB and

$$
H_{S S, M E T}=\frac{K_{M E T, H} D}{\mu_{\max , H}-D}
$$

for the methanogen. Whichever of these values is smaller under a given set of conditions will indicate the hydrogenotroph that will survive, the other being outcompeted. Similar to the case for the methanogen and the acetogen, coexistence is possible where these two steady states coincide. When sulphate is assumed abundant, this occurs at $D=0.03$, which is intuitive since this is the value of $\mu_{\max , S}$. If sulphate is not abundant, then setting the two steady state equations above equal to one another gives

$$
D \approx \frac{0.03 S}{0.05+S}
$$

Thus, as the steady state sulphate concentration $(S)$ decreases, so too must $D$ to allow for continued coexistence of both the SRB and the methanogen. For dilution rates lower than this value, the SRB will out-compete the methanogen for hydrogen, with the converse true for dilution rates above this value.

Following the same argument for the SRB and the acetogen, once again survival of both is possible under abundant sulphate at $D=0.03$, with acetogens out-competed below this value and SRB out-competed above this value. An analytical solution requires the use of the Lambert $W$ function for the case when sulphate is limiting due to the complexity of the acetogen growth rate equation, thus is not useful for this analytical analysis.

Next, in the case where lactate is available, but sulphate is not, clearly a steady state hydrogen concentration approaching the inhibitory concentration will be maintained if both the SRB and the methanogen are present, analogously to the batch culture case. Assuming a steady state hydrogen concentration of $H_{\max }$, we have the growth rate for the methanogen of

$$
\begin{aligned}
\mathcal{M}= & \frac{\mu_{\max , H}}{Y_{M E T}} \frac{H}{K_{H}+H} X_{M E T}=\frac{\mu_{\max , H}}{Y_{M E T}} \frac{H_{\max }}{K_{H}+H_{\max }} X_{M E T} \\
& \approx 0.132 X_{M E T}
\end{aligned}
$$

Thus, the dilution rate must be less than this growth rate for the methanogen to survive. Under these conditions, SRB growth will be limited by the hydrogen consumption rate of the methanogen. If the methanogen is growing at the upper limit rate of $0.132 X_{M E T}$, then hydrogen is removed from the system at the rate:

$$
0.132 X_{M E T}+D H_{\max }
$$

This is therefore the rate at which the SRB produces hydrogen to maintain the steady state. Thus:

$$
b_{L H} \mathcal{L}=0.132 X_{M E T}+D H_{\max }
$$


Hydrogenotrophs in culture at initial time

\begin{tabular}{|c|c|c|c|c|c|c|c|c|}
\hline & & $\begin{array}{l}\text { SRB }+ \text { Methanogen }+ \\
\text { Acetogen }\end{array}$ & SRB + Methanogen & SRB + Acetogen & Methanogen + Acetogen & SRB only & $\begin{array}{l}\text { Methanogen } \\
\text { only }\end{array}$ & $\begin{array}{l}\text { Acetogen } \\
\text { only }\end{array}$ \\
\hline \multirow[t]{5}{*}{$\begin{array}{l}\text { Substrates supplied in } \\
\text { abundance to culture }\end{array}$} & $\begin{array}{l}\text { Lactate + } \\
\text { Sulphate + } \\
\text { Hydrogen }\end{array}$ & $\begin{array}{l}\text { Analogous to Sulphate }+ \\
\text { Hydrogen case as high } \\
\text { hydrogen concentration } \\
\text { prevents lactate metabolism } \\
\text { by SRB }\end{array}$ & $\begin{array}{l}\text { Analogous to Sulphate + } \\
\text { Hydrogen case as high } \\
\text { hydrogen concentration } \\
\text { prevents lactate metabolism } \\
\text { by SRB }\end{array}$ & $\begin{array}{l}\text { Analogous to Sulphate }+ \\
\text { Hydrogen case as high } \\
\text { hydrogen concentration } \\
\text { prevents lactate metabolism } \\
\text { by SRB }\end{array}$ & $\begin{array}{l}\text { Coexistence at } \\
D=0.09861 \text {, acetogen } \\
\text { out-competes methanogen } \\
\text { above this and methanogen } \\
\text { out-competes acetogen } \\
\text { below this }\end{array}$ & $\begin{array}{l}\text { Survival if } \\
D \leq u_{\text {max,S }} \text { as lactate } \\
\text { metabolism inhibited by } \\
\text { high hydrogen } \\
\text { concentration }\end{array}$ & $\begin{array}{l}\text { Survival if } \\
D \leq u_{\max , M}\end{array}$ & \\
\hline & $\begin{array}{l}\text { Lactate + } \\
\text { Sulphate }\end{array}$ & $\begin{array}{l}\text { SRB survival if } \\
D \leq u_{\text {max }, L}+u_{\text {max }, S} \text {. Others } \\
\text { washed out due to } \\
\text { out-competition for } \\
\text { hydrogen or no hydrogen } \\
\text { production if SRB washed } \\
\text { out }\end{array}$ & $\begin{array}{l}\text { SRB survival if } \\
D \leq u_{\max , L}+u_{\max , S} \\
\text { Methanogen washout due } \\
\text { to out-competition for } \\
\text { hydrogen or no hydrogen } \\
\text { production if SRB washed } \\
\text { out }\end{array}$ & $\begin{array}{l}\text { SRB survival if } \\
D \leq u_{\max , L}+u_{\max , S} \text {. } \\
\text { Acetogen washout due to } \\
\text { either out-competition for } \\
\text { hydrogen or no hydrogen } \\
\text { production if SRB washed } \\
\text { out }\end{array}$ & & $\begin{array}{l}\text { Survival if } \\
D \leq u_{\max , L}+u_{\max , S}\end{array}$ & & \\
\hline & $\begin{array}{l}\text { Lactate }+ \\
\text { Hydrogen }\end{array}$ & $\begin{array}{l}\text { SRB washout as high } \\
\text { hydrogen concentration } \\
\text { prevents lactate } \\
\text { metabolism. Methanogen } \\
\text { and acetogen coexistence } \\
\text { at } D=0.09861 \text {, acetogen } \\
\text { out-competes methanogen } \\
\text { above this and methanogen } \\
\text { out-competes acetogen } \\
\text { below this }\end{array}$ & $\begin{array}{l}\text { Methanogen growth. SRB } \\
\text { washout due to hydrogen } \\
\text { concentrations above the } \\
\text { inhibitory concentration }\end{array}$ & $\begin{array}{l}\text { Acetogen growth. SRB } \\
\text { washout due to hydrogen } \\
\text { concentrations above the } \\
\text { inhibitory concentration }\end{array}$ & $\begin{array}{l}\text { Coexistence at } \\
D=0.09861 \text {, acetogen } \\
\text { out-competes methanogen } \\
\text { above this and methanogen } \\
\text { out-competes acetogen } \\
\text { below this }\end{array}$ & $\begin{array}{l}\text { Washout as lactate } \\
\text { metabolism inhibited by } \\
\text { high hydrogen } \\
\text { concentration }\end{array}$ & $\begin{array}{l}\text { Survival if } \\
D \leq U_{\max , M}\end{array}$ & \\
\hline & $\begin{array}{l}\text { Sulphate + } \\
\text { Hydrogen }\end{array}$ & $\begin{array}{l}\text { Coexistence of SRB and } \\
\text { methanogen at } D=0.03 \text {, } \\
\text { acetogen out-competed for } \\
\text { hydrogen. SRB only below } \\
\text { this value. Methanogen and } \\
\text { acetogen coexistence at } \\
D=0.09861 \text {. Methanogen } \\
\text { only between these bounds, } \\
\text { acetogen only above the } \\
\text { upper bound }\end{array}$ & $\begin{array}{l}\text { Coexistence only possible } \\
\text { at } D=0.03 \text {. Methanogens } \\
\text { out-competed for hydrogen } \\
\text { at lower dilution rates, SRB } \\
\text { washed out at higher } \\
\text { dilution rates }\end{array}$ & $\begin{array}{l}\text { Coexistence only possible } \\
\text { at } D=0.03 \text {. Acetogens } \\
\text { out-competed for hydrogen } \\
\text { at lower dilution rates, SRB } \\
\text { washed out at higher } \\
\text { dilution rates }\end{array}$ & $\begin{array}{l}\text { Coexistence at } \\
D=0.09861 \text {, acetogen } \\
\text { out-competes methanogen } \\
\text { above this and methanogen } \\
\text { out-competes acetogen } \\
\text { below this }\end{array}$ & $\begin{array}{l}\text { Survival if } \\
D \leq u_{\max , S}\end{array}$ & $\begin{array}{l}\text { Survival if } \\
D \leq u_{\max , M}\end{array}$ & \\
\hline & $\begin{array}{l}\text { Lactate } \\
\text { only }\end{array}$ & $\begin{array}{l}\text { Analogous to SRB + } \\
\text { Methanogen case, since } \\
\text { acetogen's hydrogen } \\
\text { threshold for meaningful } \\
\text { growth is much higher than } \\
\text { methanogen's. Either } \\
\text { survival of SRB and } \\
\text { methanogen only, or all are } \\
\text { washed out. }\end{array}$ & $\begin{array}{l}\text { Both survive if } D / X_{M E T} \\
\text { sufficiently small. Otherwise, } \\
\text { SRB alone may survive if at } \\
\text { steady state } D, X_{\text {SRB }} \text { and } H \\
\text { satisfy boundary conditions, } \\
\text { else both will be washed out }\end{array}$ & $\begin{array}{l}\text { Both survive if } D / X_{A C E} \\
\text { sufficiently small. Otherwise, } \\
\text { SRB alone may survive if at } \\
\text { steady state } D, X_{S R B} \text { and } H \\
\text { satisfy boundary conditions, } \\
\text { else both will be washed out }\end{array}$ & & $\begin{array}{l}\text { Survival if at steady } \\
\text { state } D, X_{S R B} \text { and } H \\
\text { satisfy boundary } \\
\text { conditions }\end{array}$ & & \\
\hline
\end{tabular}




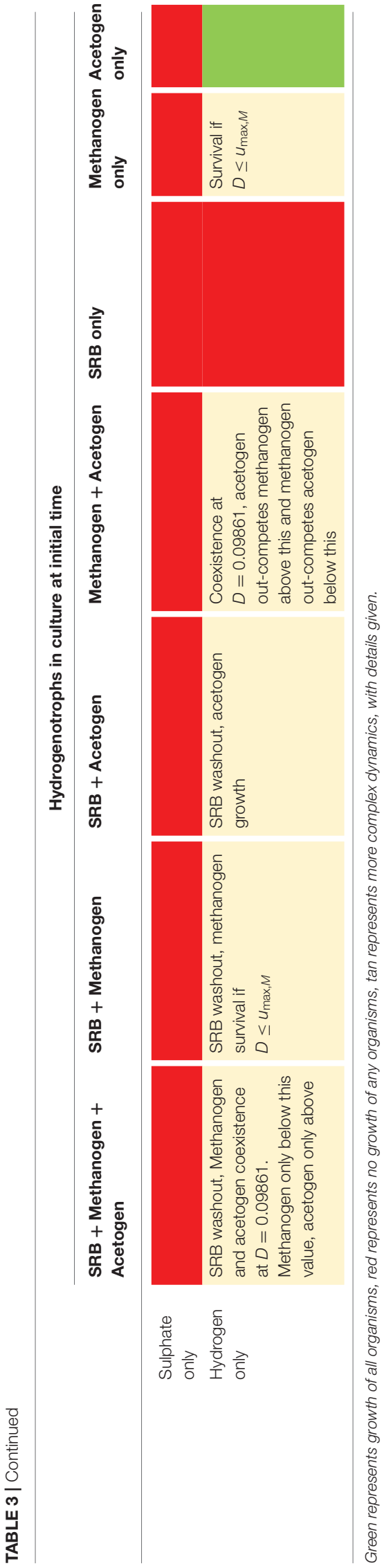

and since the rate of growth of the SRB is $Y_{S R B, L} \mathcal{L}$, we have the SRB growth rate of:

$$
\begin{aligned}
Y_{S R B, L} \mathcal{L} & =\frac{Y_{S R B, L}}{b_{L H}}\left(0.132 X_{M E T}+D H_{\max }\right) \approx 2.98 \times 10^{-4} X_{M E T} \\
& +4.88 \times 10^{-5} \mathrm{D}
\end{aligned}
$$

Since the dilution rate must be lower than the growth rate of both the SRB and the methanogen for coexistence to be sustained, we see that coexistence of the SRB and the methanogen in the presence of excess lactate is possible only when the dilution rate is very low and the methanogen cell concentration sufficiently high.

Following the same argument, we may also derive coculture survival conditions for the SRB and the acetogen. In this case, the growth rate for the acetogen at the hydrogen inhibition concentration is $4.41 \times 10^{-4} X_{A C E}\left(\mathrm{~g} \mathrm{~L}^{-1} \mathrm{~h}^{-1}\right)$ and the corresponding SRB growth rate is $\sim 4.88 \times 10^{-4} X_{A C E}+4.88 \times$ $10^{-5} D\left(\mathrm{~g} \mathrm{~L}^{-1} \mathrm{~h}^{-1}\right)$.

Table 3 outlines the outcomes of all possible culture combinations under excess substrate inflow based on the conclusions of the analytical derivations described previously. For the cases where multiple substrates are present, but at limiting concentrations, we turn to a computational analysis of outcomes.

\section{Numerical Analysis of the Model Under Continuous Culture Conditions}

In order to investigate survival of the hydrogenotrophs under mixed culture conditions, substrate inflow and dilution rate ranges were examined. These ranges were chosen as they provide coverage of conditions that allow for growth of all three hydrogenotrophs individually and allow for examination of transitions in culture dominance between the microbes. Moreover, since the motivation for this study is the behavior of hydrogenotrophs in the human GIT, substrate concentrations comparable to concentrations expected in this environment were deemed appropriate. The substrate ranges investigated were: lactate $0-25 \mathrm{mM} \mathrm{h}^{-1}$ (Vernia et al., 1988; Macfarlane and Macfarlane, 2012; Pham et al., 2017); sulphate $0-10 \mathrm{mM} \mathrm{h}^{-1}$ (Florin et al., 1991; Lewis and Cochrane, 2007); and hydrogen 0$50 \mathrm{mM} \mathrm{h}^{-1}$ (Carbonero et al., 2012; Wolf et al., 2016). The range of dilution rates was $0.01-0.15 \mathrm{~h}^{-1}$, as only acetogen survival is possible above this range under current model assumptions. The substrate inflow ranges were split into $1 \mathrm{mM} \mathrm{h}^{-1}$ intervals, and the dilution rate range was split into $0.01 \mathrm{~h}^{-1}$ intervals. The mathematical model was then run for all 218,790 possible combinations of these inflow and dilution rates to establish whether each hydrogenotroph survived the culture conditions. Initial cell concentration for each hydrogenotroph was set at $1 \mathrm{~g} \mathrm{~L}^{-1}$, and the initial concentration of each of the three substrates was set at the maximum value of its range. Each microbe was determined to have survived if, after $1,000 \mathrm{~h}$ of simulated continuous culture, its cell concentration was $>1 \times$ $10^{-4} \mathrm{~g} \mathrm{~L}^{-1}$ and its population was not decreasing. The population was determined to be still decreasing if, over the final $20 \mathrm{~h}$ of simulation, the cell concentration decreased by more than 1 


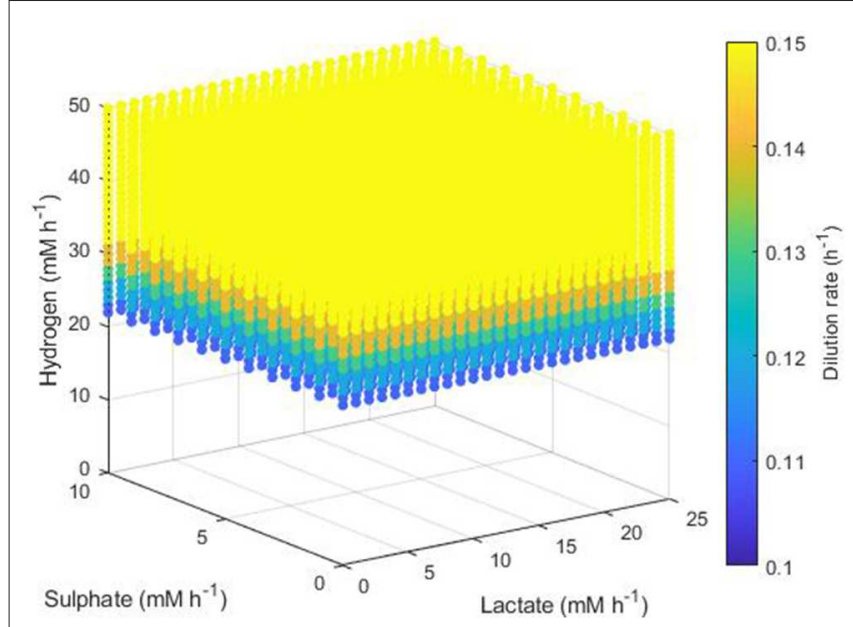

FIGURE 8 | Maximum dilution rates $\left(\mathrm{h}^{-1}\right)$ under which the outcome of the model was survival of the acetogen only. The axes indicate the inflow rate of each of the three substrates, and the colored points represent combinations of these inflows that resulted in survival of the acetogen only at the dilution rate shown on the color bar.

$\times 10^{-9} \mathrm{~g} \mathrm{~L}^{-1}$. If the microbe failed to satisfy these survival conditions, it was deemed extinct from the culture.

Of the 218,790 simulated metabolite inflow and dilution rate combinations, under no conditions were all three hydrogenotrophs coexisting after $1,000 \mathrm{~h}$, as expected from the analytical investigation of the model. Similarly, under no conditions was coexistence of the acetogen with either of the other hydrogenotrophs possible. The only possible coexisting pair was the SRB and the methanogen. Each of the three hydrogenotrophs could outcompete the other two under certain conditions, and there were also many conditions under which all three were washed out.

The simplest set of conditions to examine was those in which the acetogen outcompeted the other two hydrogenotrophs. Figure 8 shows the maximum dilution rates under which only the acetogen survived to $1,000 \mathrm{~h}$. This survival was independent of the lactate and sulphate inflow, but required a hydrogen inflow of at least $22 \mathrm{mM} \mathrm{h}^{-1}$. As hydrogen inflow increased above this cut-off, the acetogen was able to outcompete the others and survive at greater dilution rates. Note that out-competition by the acetogen occurred only when the dilution rate was above 0.1 $\mathrm{h}^{-1}$; it was earlier stated that $0.146 \mathrm{~h}^{-1}$ and $0.1042 \mathrm{~h}^{-1}$ were the greatest dilution rates under which the SRB and methanogen could survive, respectively.

Conditions resulting in survival of only the methanogen took a more complex form. Figure 9 shows the minimum dilution rate under which only this microbe survives. At low lactate, low sulphate, high hydrogen inflows, the methanogen outcompetes the other hydrogenotrophs at most dilution rates. However, as lactate and sulphate inflows increase, only under higher dilution rates and hydrogen inflows can the methanogen outcompete the SRB; for combinations of very high lactate and sulphate inflows with very low hydrogen inflow, the methanogen is outcompeted by the SRB regardless of dilution rate. Conversely to Figure 8 for

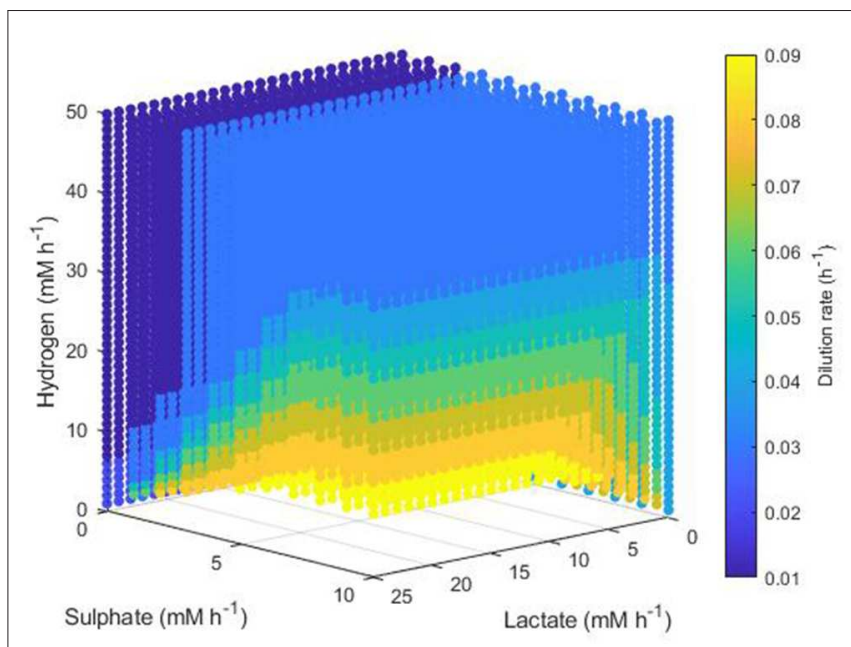

FIGURE 9 | Minimum dilution rates under which the outcome of the model was survival of the methanogen only. The axes indicate the inflow rate of each of the three substrates, and the colored points represent combinations of these inflows that resulted in survival of the methanogen only at the dilution rate shown on the color bar. Note the inverted lactate and sulfate axes.

acetogen only survival, Figure 9 shows only dilution rates up to 0.09 , as the methanogen is unable to avoid washout at dilution rates above $0.1042 \mathrm{~h}^{-1}$.

Figure 10 shows the maximum dilution rate under which the SRB outcompetes the other hydrogenotrophs. When sulphate and lactate inflows were high and hydrogen inflow was low, the SRB was able to outcompete the other microbes at dilution rates up to $0.1 \mathrm{~h}^{-1}$. This result was unaffected by lactate inflow. However, as hydrogen inflow increases, inhibition of lactate utilization by the SRB increases also, thus the SRB were only able to outcompete at low dilution rates. The same was true for low sulphate inflows.

The final set of conditions that did not result in extinction of all three hydrogenotrophs were those that enabled survival of both the SRB and the methanogen, as shown in Figure 11. The greatest dilution rate which resulted in this coexistence was $0.02 \mathrm{~h}^{-1}$, emphasizing the low growth rates achieved by both microbes at hydrogen concentrations approaching the inhibitory concentration, as shown earlier analytically. Coexistence was unaffected by lactate concentration, but did require a relationship between he sulphate and hydrogen inflows: high hydrogen inflows had to coincide with high sulphate inflows to maintain survival of both the SRB and the methanogen. Coexistence also required a minimum hydrogen inflow of $6 \mathrm{mM}$ and was not possible at zero sulphate inflow. The blue region in Figure 11 indicates conditions under which a dilution rate of $0.01 \mathrm{~h}^{-1}$ did not result in coexistence, although this is likely a result of the model not reaching steady state after $1,000 \mathrm{~h}$, as discussed below. It is anticipated that all colored points in Figure 11 represent conditions that would allow for survival of both the SRB and the methanogen at either 0.01 or $0.02 \mathrm{~h}^{-1}$ dilution rates.

The results shown in this numerical section, and in particular those shown in Figure 11, may not be reflective of steady state 


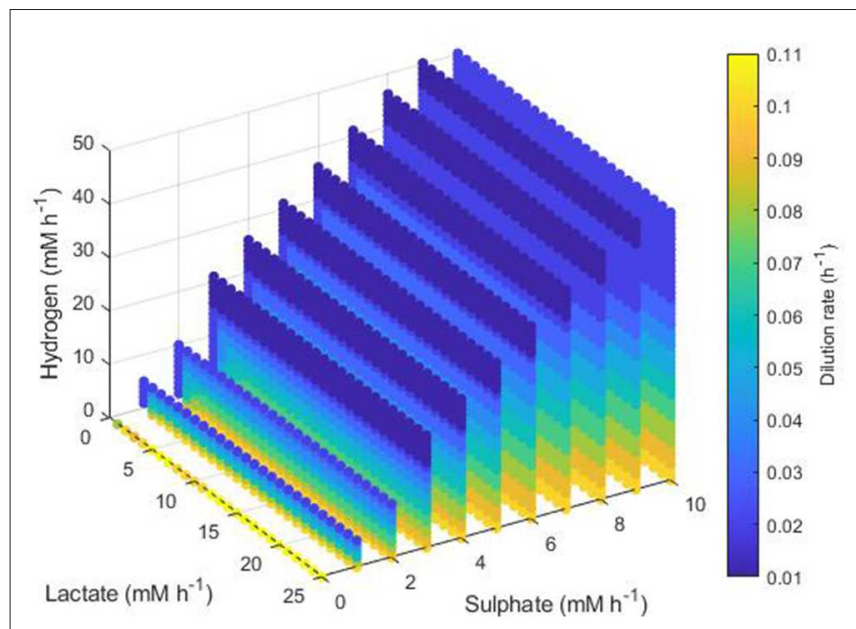

FIGURE 10 | Maximum dilution rates under which the outcome of the model was survival of the SRB only. The axes indicate the inflow rate of each of the three substrates, and the colored points represent combinations of these inflows that resulted in survival of the SRB only at the dilution rate shown on the color bar. Note the inverted lactate axis.

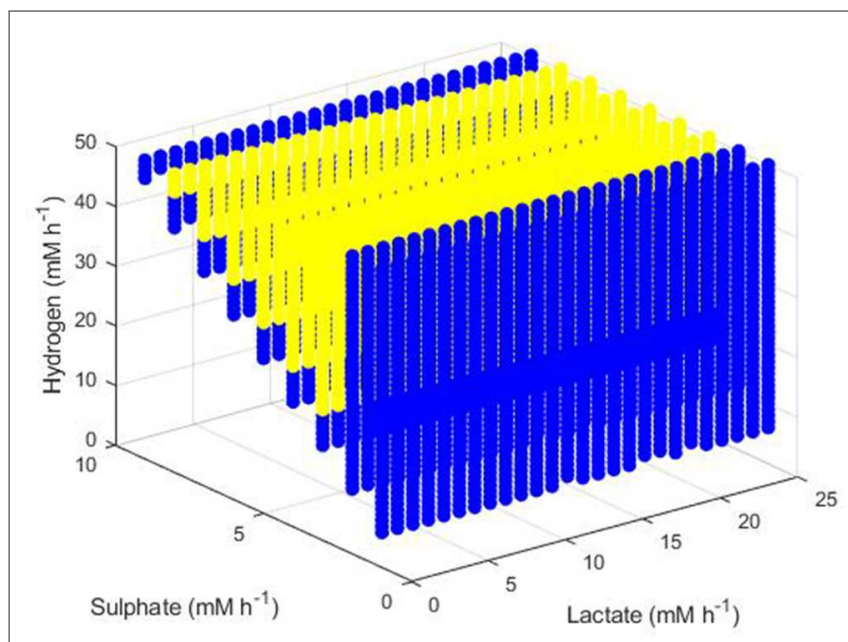

FIGURE 11 | Dilution rates under which the outcome of the model was survival of the SRB and the methanogen. The axes indicate the inflow rate of each of the three substrates. Yellow points indicate conditions where coexistence was possible at both 0.01 and $0.02 \mathrm{~h}^{-1}$ dilution rates and blue points indicate conditions where coexistence was only possible at a dilution rate of $0.02 \mathrm{~h}^{-1}$.

survival. Under our assumptions, these results merely indicate survival and very slow cell concentration change after $1,000 \mathrm{~h}$ of simulated culture. The low dilution rates considered may result in a longer time required for the model to reach steady state under certain conditions, so the above results are not necessarily steady state results in all cases. However, when the conditions resulting in SRB and methanogen coexistence were simulated for $2,000 \mathrm{~h}$, the survival status was identical to the $1,000 \mathrm{~h}$ case, making steady state survival likely. Moreover, survival of a microbial population after $1,000 \mathrm{~h}$ likely translates to survival under practical, shorter timeframes.

\section{DISCUSSION}

A number of previous studies suggested that a degree of competitive exclusion exists between hydrogenotrophs when competing for hydrogen in the human GIT (Gibson et al., 1988a,b, 1990, 1993; Strocchi et al., 1994). However, more recent work has found that all three hydrogenotrophs are present in the GIT of all tested individuals (Nava et al., 2012). There exists a great body of research detailing the dominant hydrogenotroph in different human populations and in different locations in the GIT, as well as the influence of dietary changes on this dominance (for a review, see Smith et al., 2019b). The modelling work presented here shows that under conditions of abundant substrate in a homogeneously mixed environment, dominance of a culture by one species is the most common result, with extinction of the others. Moreover, under low-dilution, high-substrate conditions, the model results support the established hierarchy between $\mathrm{SRB}$, methanogens and acetogens in terms of their growth rates and competitiveness.

The prediction of the model that coexistence of all three hydrogenotrophs in continuous culture is impossible under any of the substrate and dilution rate combinations considered is in contrast with their observation is natural habitats, such as the human GIT (Nava et al., 2012). However, the model assumption of a homogeneously mixed environment is likely partially responsible for this difference. In natural habitats, spatial separation, diffusion of metabolites, biofilm formation and many other heterogeneities will contribute both positively and negatively to the growth of each of the hydrogenotrophs. For example, being separated spatially from the methanogen would allow for better growth by the acetogen due to reduced local competition for hydrogen, whereas the same spatial separation from the SRB may be detrimental to the acetogen if it is reliant on cross-feeding for released hydrogen.

Also neglected in this model is the metabolism of substrates other than hydrogen, lactate and sulphate by the hydrogenotrophs. Several GIT SRB strains have been shown to metabolize other organic substrates (Willis et al., 1997), as have GIT acetogens (Bernalier et al., 1996). Formate is a molecule that has been shown to be metabolized by strains of all three hydrogenotrophs (Bernalier et al., 1996; Samuel et al., 2007; da Silva et al., 2013), and would be a valuable addition to the tri-culture model. However, the addition of this extra metabolite would make analytical solutions to the model more challenging to obtain, and numerical results more challenging to interpret.

It is not expected that the parameter values determined from monoculture experiments stated in Table 1 will be suitable for all hydrogenotroph strains in all environments, as gene expression changes between monoculture and co-culture have been shown in SRB and methanogen co-cultures previously (Walker et al., 2009; Meyer et al., 2013). The model results demonstrated that survival of more than one hydrogenotroph under continuous culture conditions was only possible under a small set of conditions, and we would not expect this qualitative result of the model to change given small variations to the parameter values. However, so long as the assumptions on the 
model system remain unchanged, the analytical results provided here will still apply. If the assumptions change or large variations to the parameter values are made, a revised analysis of the model would be required.

The applicability of the model to natural environments is also of interest. Coexistence of multiple hydrogenotrophs was shown to be possible only under a very limited set of conditions in the model. Small deviations due to external, non-modelled influences would be expected to occur in natural environments. Under the model conclusions, these small deviations would rapidly lead to extinction of all or all but one of the modelled organisms. However, the observed coexistence of hydrogenotrophs in natural environments indicates that other factors have an influence. In the human GIT, these other factors may be the use of alternative metabolites, spatial separation of hydrogenotrophs and interactions with the wider microbiota and host. Also not addressed by this model was the potential for metabolite influx to follow a periodic or inconsistent pattern, as would be expected in the GIT. The influence of all these factors on GIT survival of hydrogenotrophs should be included and investigated in future models.

Inclusion of the non-modelled influences mentioned above in future modelling efforts for hydrogenotroph metabolism in the GIT will be challenging, but the tools exist for such investigations. Several spatial models of microbial growth and metabolism have been developed, using both continuous (for example, see Alpkvist et al., 2006) and discrete spatial distribution (for example, see Bauer et al., 2017). There are also microbiome models that incorporate various host influences, such as $\mathrm{pH}$ buffering and water absorption (Cremer et al., 2017), the secreted mucus layer and fluid dynamics of the intestinal contents under peristaltic movement (Labarthe et al., 2019). Finally, the influence of interactions amongst the microbiota can be studied with existing microbial community models (for examples, see Motelica-Wagenaar et al., 2014; Kettle et al., 2017, and Sung et al., 2017). These models were more comprehensive and applicable to the GIT than that presented here, but hydrogenotrophic microbes have thus far been either absent or only a minor part of these large-scale models. Both the study of these microbes and the large-scale models themselves could benefit from the inclusion of hydrogenotrophs.

The complexity of the conditions for survival derived from the relatively simple model presented here, which features only three different organisms and six metabolites (three of which had no determining effect on the model outcomes), in a homogenously mixed medium with no gaseous phase,

\section{REFERENCES}

Alpkvist, E., Picioreanu, C., Van Loosdrecht, M. C. M., and Heyden, A. (2006). Three-dimensional biofilm model with individual cells and continuum EPS matrix. Biotechnol. Bioeng. 94, 961-979. doi: 10.1002/bit.20917

Archer, D. B., and Powell, G. E. (1985). Dependence of the specific growth rate of methanogenic mutualistic cocultures on the methanogen. Arch. Microbiol. 141, 133-137. doi: 10.1007/BF00423273 demonstrates the difficulty in extracting universal insight into large, complex populations from mathematical models. However, mathematical modelling has been used to successfully glean more information from experimental data for co- and tricultures of human GIT bacteria (Van Wey et al., 2014; Pinto et al., 2017; D'Hoe et al., 2018) and for cross-feeding cultures of SRB and methanogens in the past (Archer and Powell, 1985; Stolyar et al., 2007). These successes justify the further use of modelling to explore areas that cannot easily be studied experimentally. We are not aware of any research in which the three hydrogenotrophs modelled here have been tri-cultured together, thus the results of the model currently forms the best predictive capability available for what would be observed experimentally. Moreover, the simple nature of the constituent models will allow for straightforward inclusion of additional variables and conditions, such as formate metabolism. Although an increase in complexity will likely prevent analytical solutions to the model equations, model simulations can still provide useful insight into microbial community dynamics.

To conclude, the results of the mathematical model show that coexistence of all three hydrogenotrophs in the human GIT must be due to selective factors outside of the hydrogen, lactate and sulphate metabolism and varied dilution rates considered here, since it was impossible to obtain coexistence of the three in continuous culture under the model assumptions. The influence of these other selective factors needs to be examined in future models investigating hydrogenotroph dynamics in the GIT.

\section{DATA AVAILABILITY STATEMENT}

The raw data supporting the conclusions of this article will be made available by the authors, without undue reservation, to any qualified researcher.

\section{AUTHOR CONTRIBUTIONS}

All authors contributed to the conceptualization of the model. NS performed the modelling work and wrote the manuscript. All authors contributed to the revision of the manuscript.

\section{FUNDING}

NS was supported by a Ph.D. fellowship from the Riddet Institute, through funding provided by the New Zealand Tertiary Education Commission. 
Bernalier, A., Willems, A., Leclerc, M., Rochet, V., and Collins, M. D. (1996). Ruminococcus hydrogenotrophicus sp. nov., a new H2/CO2-utilizing acetogenic bacterium isolated from human feces. Arch. Microbiol. 166, 176-183. doi: $10.1007 / \mathrm{s} 002030050373$

Carbonero, F., Benefiel, A. C., and Gaskins, H. R. (2012). Contributions of the microbial hydrogen economy to colonic homeostasis. Nat. Rev. Gastroenterol. Hepatol. 9, 504-518. doi: 10.1038/nrgastro. 2012.85

Cremer, J., Arnoldini, M., and Hwa, T. (2017). Effect of water flow and chemical environment on microbiota growth and composition in the human colon. Proc. Natl. Acad. Sci. U.S.A. 114, 6438-6443. doi: 10.1073/pnas.1619598114

da Silva, S. M., Voordouw, J., Leitão, C., Martins, M., Voordouw, G., and Pereira, I. A. C. (2013). Function of formate dehydrogenases in Desulfovibrio vulgaris hildenborough energy metabolism. Microbiology 159, 1760-1769. doi: 10.1099/mic.0.067868-0

D’Hoe, K., Vet, S., Faust, K., Moens, F., Falony, G., Gonze, D., et al. (2018). Integrated culturing, modeling and transcriptomics uncovers complex interactions and emergent behavior in a three-species synthetic gut community. eLife 7:e37090. doi: 10.7554/eLife.37090.036

Falony, G., Vlachou, A., Verbrugghe, K., and De Vuyst, L. (2006). Cross-feeding between Bifidobacterium longum BB536 and acetate-converting, butyrateproducing colon bacteria during growth on oligofructose. Appl. Environ. Microbiol. 72, 7835-7841. doi: 10.1128/AEM.01296-06

Florin, T., Neale, G., Gibson, G. R., Christl, S. U., and Cummings, J. H. (1991). Metabolism of dietary sulphate: absorption and excretion in humans. Gut 32, 766-773. doi: 10.1136/gut.32.7.766

Ghoshal, U., Shukla, R., Srivastava, D., and Ghoshal, U. C. (2016). Irritable bowel syndrome, particularly the constipation-predominant form, involves an increase in Methanobrevibacter smithii, which is associated with higher methane production. Gut Liver 10, 932-938. doi: 10.5009/gnl15588

Gibson, G. R., Cummings, J. H., and Macfarlane, G. T. (1988a). Competition for hydrogen between sulphate-reducing bacteria and methanogenic bacteria from the human large intestine. J. Appl. Bacteriol. 65, 241-247. doi: 10.1111/j.1365-2672.1988.tb01891.x

Gibson, G. R., Cummings, J. H., Macfarlane, G. T., Allison, C., Segal, I., Vorster, H. H., et al. (1990). Alternative pathways for hydrogen disposal during fermentation in the human colon. Gut 31, 679-683. doi: 10.1136/gut.31.6.679

Gibson, G. R., Macfarlane, G. T., and Cummings, J. H. (1988b). Occurrence of sulphate-reducing bacteria in human faeces and the relationship of dissimilatory sulphate reduction to methanogenesis in the large gut. J. Appl. Microbiol. 65, 103-111. doi: 10.1111/j.1365-2672.1988.tb01498.x

Gibson, G. R., Macfarlane, S., and Macfarlane, G. T. (1993). Metabolic interactions involving sulphate-reducing and methanogenic bacteria in the human large intestine. FEMS Microbiol. Ecol. 12, 117-125. doi: 10.1111/j.1574-6941.1993.tb00023.x

Healey, G. R., Murphy, R., Brough, L., Butts, C. A., and Coad, J. (2017). Interindividual variability in gut microbiota and host response to dietary interventions. Nutr. Rev. 75, 1059-1080. doi: 10.1093/nutrit/nux062

Junicke, H., Feldman, H., Van Loosdrecht, M. C. M., and Kleerebezem, R. (2016). Limitation of syntrophic coculture growth by the acetogen. Biotechnol. Bioeng. 113, 560-567. doi: 10.1002/bit.25816

Kalyuzhnyi, S. V., and Fedorovich, V. V. (1998). Mathematical modelling of competition between sulphate reduction and methanogenesis in anaerobic reactors. Bioresour. Technol. 65, 227-242. doi: 10.1016/S0960-8524(98)00019-4

Kettle, H., Holtrop, G., Louis, P., and Flint, H. J. (2017). microPop: modelling microbial populations and communities in R. Methods Ecol. Evol. 9, 399-409. doi: 10.1111/2041-210X.12873

Kettle, H., Louis, P., Holtrop, G., Duncan, S. H., and Flint, H. J. (2015). Modelling the emergent dynamics and major metabolites of the human colonic microbiota. Environ. Microbiol. 17, 1615-1630. doi: 10.1111/1462-2920.12599

Khelaifia, S., and Drancourt, M. (2012). Susceptibility of archaea to antimicrobial agents: applications to clinical microbiology. Clin. Microbiol. Infect. 18, 841-848. doi: 10.1111/j.1469-0691.2012.03913.x

Khelaifia, S., Raoult, D., and Drancourt, M. (2013). A versatile medium for cultivating methanogenic archaea. PLoS ONE 8:e61563. doi: 10.1371/journal.pone.0061563

Labarthe, S., Polizzi, B., Phan, T., Goudon, T., Ribot, M., and Laroche, B. (2019). A mathematical model to investigate the key drivers of the biogeography of the colon microbiota. J. Theor. Biol. 462, 552-581. doi: 10.1016/j.jtbi.2018. 12.009

Leclerc, M., Bernalier, A., Donadille, G., and Lelait, M. (1997). $\mathrm{H}_{2} / \mathrm{CO}_{2}$ metabolism in acetogenic bacteria isolated from the human colon. Anaerobe 3, 307-315. doi: 10.1006/anae.1997.0117

Lewis, S., and Cochrane, S. (2007). Alteration of sulfate and hydrogen metabolism in the human colon by changing intestinal transit rate. Am. J. Gastroenterol. 102, 624-633. doi: 10.1111/j.1572-0241.2006.01020.x

Lynch, T. A., Wang, Y., van Brunt, B., Pacheco, D., and Janssen, P. H. (2019). Modelling thermodynamic feedback on the metabolism of hydrogenotrophic methanogens. J. Theor. Biol. 477, 14-23. doi: 10.1016/j.jtbi.2019.05.018

Macfarlane, G. T., and Macfarlane, S. (2012). Bacteria, colonic fermentation, and gastrointestinal health. J. AOAC Int. 95, 50-60. doi: 10.5740/jaoacint.SGE_Macfarlane

Meyer, B., Kuehl, J., Deutschbauer, A. M., Price, M. N., Arkin, A. P., and Stahl, D. A. (2013). Variation among desulfovibrio species in electron transfer systems used for syntrophic growth. J. Bacteriol. 195, 990-1004. doi: 10.1128/JB.01959-12

Monod, J. (1949). The growth of bacterial cultures. Annu. Rev. Microbiol. 3, 371-394. doi: 10.1146/annurev.mi.03.100149.002103

Morrison, D. J., and Preston, T. (2016). Formation of short chain fatty acids by the gut microbiota and their impact on human metabolism. Gut Microbes 7 , 189-200. doi: 10.1080/19490976.2015.1134082

Motelica-Wagenaar, A. M., Nauta, A., van den Heuvel, E. G. H. M., and Kleerebezem, R. (2014). Flux analysis of the human proximal colon using anaerobic digestion model 1. Anaerobe 28, 137-148. doi: 10.1016/j.anaerobe.2014.05.008

Muñoz-Tamayo, R., Popova, M., Tillier, M., Morgavi, D. P., Morel, J. P., Fonty, G., et al. (2019). Hydrogenotrophic methanogens of the mammalian gut: functionally similar, thermodynamically different-A modelling approach. PLoS ONE 14:e226243. doi: 10.1371/journal.pone.0226243

Nava, G. M., Carbonero, F., Croix, J. A., Greenberg, E., and Gaskins, H. R. (2012). Abundance and diversity of mucosa-associated hydrogenotrophic microbes in the healthy human colon. ISME J. 6, 57-70. doi: 10.1038/ismej.2011.90

Noguera, D. R., Brusseau, G. A., Rittmann, B. E., and Stahl, D. A. (1998). A unified model describing the role of hydrogen in the growth of desulfovibrio vulgaris under different environmental conditions. Biotechnol. Bioeng. 59, 732-746. doi: 10.1002/(SICI)1097-0290(19980920)59:6<732::AID-BIT10>3.0.CO;2-7

Pham, V. T., Lacroix, C., Braegger, C. P., and Chassard, C. (2017). Lactate-utilizing community is associated with gut microbiota dysbiosis in colicky infants. Sci. Rep. 7:11176. doi: 10.1038/s41598-017-11509-1

Pinto, F., Medina, D. A., Pérez-Correa, J. R., and Garrido, D. (2017). Modeling metabolic interactions in a consortium of the infant gut microbiome. Front. Microbiol. 8:2507. doi: 10.3389/fmicb.2017.02507

Qin, J., Li, R., Raes, J., Arumugam, M., Burgdorf, K. S., Manichanh, C., et al. (2010). A human gut microbial gene catalogue established by metagenomic sequencing. Nature 464, 59-65. doi: 10.1038/nature 08821

Ribes, J., Keesman, K., and Spanjers, H. (2004). Modelling anaerobic biomass growth kinetics with a substrate threshold concentration. Water Res. 38, 4502-4510. doi: 10.1016/j.watres.2004.08.017

Richards, M. A., Lie, T. J., Zhang, J., Ragsdale, S. W., Leigh, J. A., and Price, N. D. (2016). Exploring hydrogenotrophic methanogenesis: a genome scale metabolic reconstruction of methanococcus maripaludis. J. Bacteriol. 198:3379-3390. doi: 10.1128/JB.00571-16

Samuel, B. S., Hansen, E. E., Manchester, J. K., Coutinho, P. M., Henrissat, B., Fulton, R., et al. (2007). Genomic and metabolic adaptations of methanobrevibacter smithii to the human gut. Proc. Natl. Acad. Sci. U.S.A. 104, 10643-10648. doi: 10.1073/pnas.0704189104

Schiel-Bengelsdorf, B., and Dürre, P. (2012). Pathway engineering and synthetic biology using acetogens. FEBS Lett. 586, 2191-2198. doi: 10.1016/j.febslet.2012.04.043

Smith, N. W., Shorten, P. R., Altermann, E., Roy, N. C., and McNabb, W. C. (2019a). A mathematical model for the hydrogenotrophic metabolism of sulphate-reducing bacteria. Front. Microbiol. 10:1652. doi: $10.3389 /$ fmicb.2019.01652

Smith, N. W., Shorten, P. R., Altermann, E., Roy, N. C., and McNabb, W. C. (2020). Mathematical modelling supports the existence of a threshold hydrogen concentration and media-dependent yields in the 
growth of a reductive acetogen. Bioprocess Biosystems Eng. 43, 885-894. doi: 10.1007/s00449-020-02285-w

Smith, N. W., Shorten, P. R., Altermann, E. H., Roy, N. C., and McNabb, W. C. (2019b). Hydrogen cross-feeders of the human gastrointestinal tract. Gut Microbes 10, 270-288. doi: 10.1080/19490976.2018.1546522

Stolyar, S., Van Dien, S., Hillesland, K. L., Pinel, N., Lie, T. J., Leigh, J. A., et al. (2007). Metabolic modeling of a mutualistic microbial community. Mol. Syst. Biol. 3:92. doi: 10.1038/msb4100131

Strocchi, A., Furne, J., Ellis, C., and Levitt, M. D. (1994). Methanogens outcompete sulphate reducing bacteria for $\mathrm{H} 2$ in the human colon. Gut 35, 1098-1101. doi: 10.1136/gut.35.8.1098

Sung, J., Kim, S., Cabatbat, J. J. T., Jang, S., Jin, Y. S., Jung, G. Y., et al. (2017). Global metabolic interaction network of the human gut microbiota for context-specific community-scale analysis. Nat. Commun. 8:15393. doi: 10.1038/ncomms15393

Tamayo, R.M., Laroche, B., Leclerc, M., and Walter, E. (2008). "Modelling and identification of in vitro cityhomoacetogenesis by human-colon bacteria," in 2008 16th Mediterranean Conference on Control and Automation. (Ajaccio), 1717-1722. doi: 10.1109/MED.2008.4602137

Thauer, R. K., Jungermann, K., and Decker, K. (1977). Energy conservation in chemotrophic anaerobic bacteria. Bacteriol. Rev. 41, 100-180. doi: 10.1128/MMBR.41.1.100-180.1977

Van Wey, A. S., Cookson, A. L., Roy, N. C., McNabb, W. C., Soboleva, T. K., and Shorten, P. R. (2014). Monoculture parameters successfully predict coculture growth kinetics of Bacteroides thetaiotaomicron and two Bifidobacterium strains. Int. J. Food Microbiol. 191, 172-181. doi: 10.1016/j.ijfoodmicro.2014.09.006

Vernia, P., Caprilli, R., Latella, G., Barbetti, F., Magliocca, F. M., and Cittadini, M. (1988). Fecal lactate and ulcerative colitis. Gastroenterology 95, 1564-1568. doi: 10.1016/S0016-5085(88)80078-7
Walker, C. B., He, Z., Yang, Z. K., Ringbauer, J. A., He, Q., Zhou, J., et al. (2009). The electron transfer system of syntrophically grown Desulfovibrio vulgaris. J. Bacteriol. 191, 5793-5801. doi: 10.1128/JB.00 356-09

Willis, C. L., Cummings, J. H., Neale, G., and Gibson, G. R. (1997). Nutritional aspects of dissimilatory sulfate reduction in the human large intestine. Curr. Microbiol. 35, 294-298. doi: 10.1007/s0028499 00257

Wolf, P. G., Biswas, A., Morales, S. E., Greening, C., and Gaskins, H. R. (2016). H2 metabolism is widespread and diverse among human colonic microbes. Gut Microbes 7, 235-245. doi: 10.1080/19490976.2016. 1182288

Wolin, M. J., and Miller, T. L. (1983). Interactions of microbial populations in cellulose fermentation. Fed. Proc. 42, 109-113.

Zmora, N., Suez, J., and Elinav, E. (2019). You are what you eat: diet, health and the gut microbiota. Nat. Rev. Gastroenterol. Hepatol. 16, 35-56. doi: 10.1038/s41575-018-0061-2

Conflict of Interest: The authors declare that the research was conducted in the absence of any commercial or financial relationships that could be construed as a potential conflict of interest.

Copyright (C) 2020 Smith, Shorten, Altermann, Roy and McNabb. This is an openaccess article distributed under the terms of the Creative Commons Attribution License (CC BY). The use, distribution or reproduction in other forums is permitted, provided the original author(s) and the copyright owner(s) are credited and that the original publication in this journal is cited, in accordance with accepted academic practice. No use, distribution or reproduction is permitted which does not comply with these terms. 